\title{
Factors influencing heterogeneity in female reproductive success in a Critically Endangered population of bottlenose dolphins
}

\author{
T. E. Brough ${ }^{1, *}$, S. Henderson ${ }^{1,2}$, M. Guerra ${ }^{1}$, S. M. Dawson ${ }^{1}$ \\ ${ }^{1}$ Marine Mammal Research Group, Department of Marine Science, University of Otago, PO Box 56, Dunedin, New Zealand \\ ${ }^{2}$ Department of Biology, Tacoma Community College, 6501 South 19th Street, Tacoma, Washington 98466, USA
}

\begin{abstract}
For threatened species or populations, variation in reproductive success among females may be explicitly linked with vulnerability to extinction. Thus, an understanding of factors that may cause variability in reproductive success is important. The population of bottlenose dolphins in Doubtful Sound, New Zealand, has a recent history of rapid population decline and low calf survival rates. A previous study has shown high variability in calf survival among multiparous females. This study addresses the factors that seem most important in explaining variation in calf survival and thus reproductive success among females in this population. Reproductive data were sourced from a long-term photo-identification dataset, which allowed tracking the fate of 49 calves born into the population between 1995 and 2012. General linear mixed models combined with model averaging were used to assess how birth timing, maternal size, age and potential anthropogenic impacts contributed to variation in calf survival. Models show that a female's size and her ability to give birth at an optimum time in the calving season are significant predictors of calf survival to an age of 1 and 3 yr. This is the first study to demonstrate how birth timing and mother size are correlated with female reproductive success in a cetacean species. These results confirm the importance of demographic stochasticity and reproductive heterogeneity in small, threatened marine mammal populations.
\end{abstract}

KEY WORDS: Reproductive success $\cdot$ Reproductive heterogeneity $\cdot$ Survival $\cdot$ Bottlenose dolphin

\section{INTRODUCTION}

Understanding the factors influencing reproduction in threatened species may provide valuable insights into the causes of low population sizes and overall vulnerability to extinction (Craig \& Ragen 1999, Baker et al. 2007, Berger 2012). In population biology, one of the critical parameters of interest is reproductive success, which is inherently associated with the productivity and thus viability of a population (Andrén 1990, Kendall \& Fox 2002, Melbourne \& Hastings 2008). Reproductive success is often defined as the number of offspring that recruit into the adult breeding population (McGregor et al. 1981, Phillips et al. 1996). In other cases, differences in reproductive success among females are described in terms of the number of offspring that survive to a

\footnotetext{
*Corresponding author: tom.brough@otago.ac.nz
}

particular age (Mann et al. 2000, Wells et al. 2005, Henderson et al. 2014).

Reproductive success may be influenced by a range of social (Côtè \& Festa-Bianchet 2001), ecological (Atkinson \& Ramsay 1995, Festa-Bianchet \& Jorgenson 1998), behavioural (Mann et al. 2000) and morphological or physiological factors (Pomeroy et al. 1999). For example, over a wide range of taxa, offspring survival is correlated with maternal body size (Chastel et al. 1995, Fairbanks \& McGuire 1995, Pomeroy et al. 1999). Large females, for example, probably have greater resources to invest in their young during embryonic and/or post-natal development (e.g. grey seals, Iverson et al. 1993; polar bears, Atkinson \& Ramsay 1995). The timing of births may also be correlated with female reproductive success (Goldizen et al. 1988, Majluf 1992). It has been sug-

() The authors 2016. Open Access under Creative Commons by Attribution Licence. Use, distribution and reproduction are unrestricted. Authors and original publication must be credited.

Publisher: Inter-Research · www.int-res.com 
gested that this relationship is due to benevolent environmental conditions and/or resource availability increasing the likelihood of offspring survival at particular times (Ims 1990, Ransome \& McOwat 1994, Daan et al. 1988).

Individuals in many species show variation in reproductive success according to age (e.g. sea otters, Riedman et al. 1994; polar bears, Atkinson \& Ramsay 1995; southern right whales, Elwen \& Best 2004). Such a relationship may represent older, more experienced females retaining a higher position in the social hierarchy and thus being exposed to better mating opportunities (Côtè \& Festa-Bianchet 2001). Additionally, more experienced females may 'learn' the optimal conditions for giving birth through adaptive trial and error (Clutton-Brock 1984).

The effects of maternal size, birth timing and maternal age on reproductive success are largely unknown in cetaceans. To our knowledge, there has been no previous investigation of whether larger females exhibit greater reproductive success. This probably reflects the difficulty of gathering the required morphometric data. Cetaceans are among the most difficult animals to measure accurately in the wild (Dawson et al. 1995). Whilst strong birth seasonality is evident in many cetacean populations (Mann et al. 2000, Thayer et al. 2003) and studies have suggested a relationship between reproductive success and birth timing (Henderson et al. 2014, Fruet et al. 2015), the link is yet to be demonstrated.

Bottlenose dolphins are a species which is widely distributed globally and is the subject of several long-term (>20 yr) research programmes (e.g. Scott et al. 1990, Wilson et al. 1999, Mann et al. 2000, Henderson et al. 2014). Knowledge of their reproductive biology in the wild, however, is limited to documentation of reproductive rates (Mann et al. 2000, Henderson et al. 2014), birth seasonality (Urian et al. 1996, Thayer et al. 2003) and interbirth intervals (Mann et al. 2000, Henderson et al. 2014, Fruet et al. 2015). Reproduction is likely to be influenced by a range of factors that result in variation in reproductive success among years and individuals. For example, Mann et al. (2000) demonstrated that female reproductive success was influenced by the use of shallow water habitat, which may be associated with reduced calf predation or increased food resources.

The bottlenose dolphin population of Doubtful Sound has been the subject of ongoing research since 1990 (Williams et al. 1993) and is currently classified as Critically Endangered (Currey et al. 2009a). The long-term data set generated from decades of photo-identification mark-recapture sampling pro- vides the opportunity to produce detailed reproductive histories for each of the females in the population. The population has suffered periods of dramatic population decline (Currey et al. 2007), the demographic cause of which has been attributed to a decrease in calf survival rate from 0.86 (95\% CI: 0.68-0.95) prior to 2002 to 0.38 (95\% CI: $0.21-0.58$ ) for the period 2002 to 2007 (Currey et al. 2009b). Potential anthropogenic impacts due to habitat modification from a hydro-electric power station have been discussed (Currey et al. 2009a,b).

Henderson et al. (2014) demonstrated substantial heterogeneity in reproductive success among female dolphins in Doubtful Sound. Of the 18 multiparous females in the population at 2011, 6 had not had a calf survive to $3 \mathrm{yr}$ of age since 1995. In contrast, another 6 females had $70 \%$ of their calves survive between 1995 and 2011. This is despite similar numbers of calves being born to both 'good' and 'bad' mothers (Henderson et al. 2014). Calf survival in Doubtful Sound seems to be higher if a calf is born in January, which is immediately before the peak in surface water temperature (Henderson et al. 2014). This population resides near the southernmost limit for the species and is thus faced with much cooler temperatures than bottlenose dolphins in lower latitudes (Haase \& Schneider 2001). Dolphin calves are less tolerant of low water temperatures than adults due to their proportionally greater surface area and reduced blubber thickness (Yeates \& Houser 2008). The thermal stresses imposed by being born into a cool water environment may cause high calf mortality for individuals not born at the optimum time (Henderson et al. 2014).

This study assessed how a range of measurable factors (mother size, mother age, and birth timing) and potential anthropogenic impacts contribute to female reproductive success. This was undertaken by assessing calf survival to 1 and $3 \mathrm{yr}$ of age for each of the reproductively active females in the population of Doubtful Sound. Quantifying how these factors influence female reproductive success will facilitate understanding the drivers of population trends in Doubtful Sound, which are likely to be relevant to other small, threatened marine mammal populations.

\section{MATERIALS AND METHODS}

\section{Photo-identification surveys}

Photo-identification surveys of bottlenose dolphins in Doubtful Sound (Fig. 1) have been carried out 


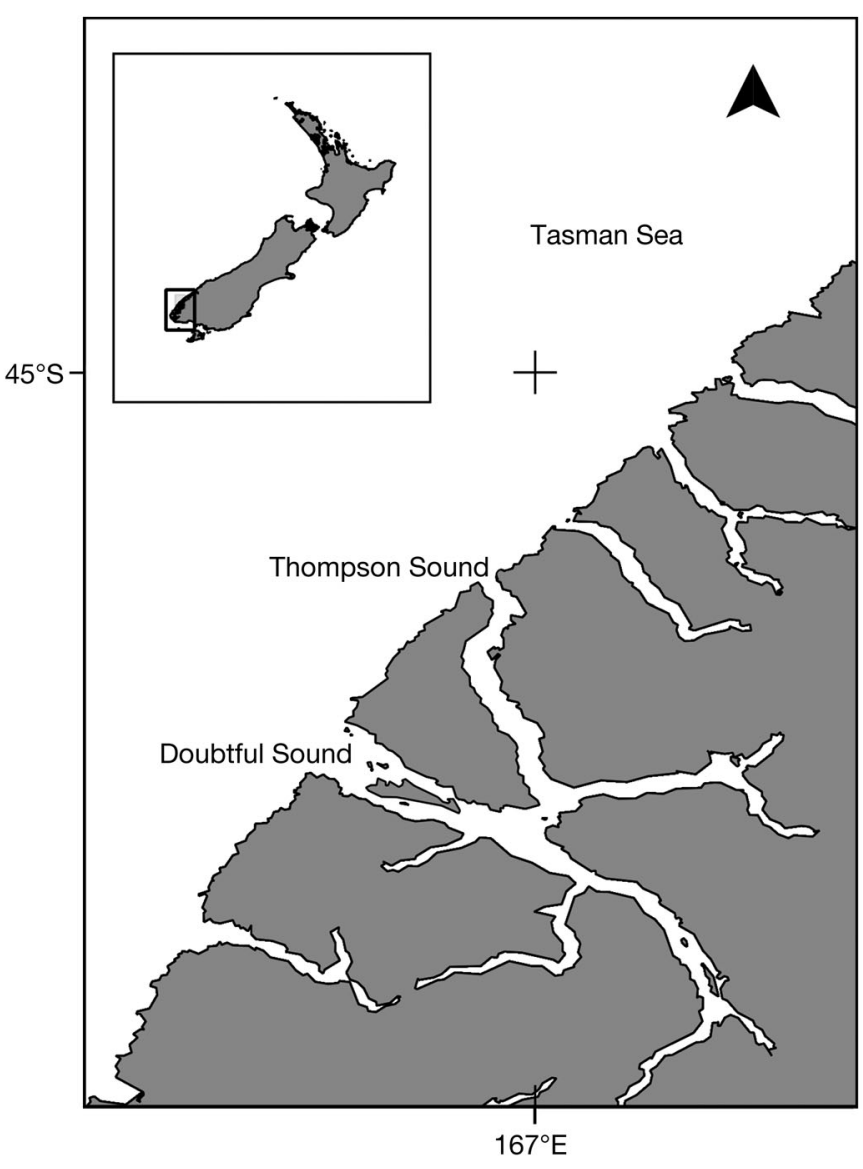

Fig. 1. Doubtful Sound complex showing the main fiords of Thompson and Doubtful Sound. Inset shows the position of Fiordland along the New Zealand coast

since 1990 (Williams et al. 1993) following a predefined route. Photographs were taken using Nikon SLR and DSLR cameras, mostly with 80-200 mm f2.8 and $300 \mathrm{~mm}$ f4 AF Nikkor lenses. Field and photoidentification protocols are described in detail in Williams et al. (1993) and Currey et al. (2009b).

\section{Reproductive data}

Reproductive histories over the period between 1995 and 2012 were available for all adult females in the Doubtful Sound population that were still alive at the end of $2012(n=19)$. These females gave birth to 49 calves that were included in this analysis. Due to a high frequency of sampling trips $\left(\right.$ mean $=14 \mathrm{mo}^{-1}$ ) over the months during which calves are born (September to April; see Supplement 1 at www.int-res.com/ articles/suppl/n029p255_supp.pdf for research effort), birth month is known for most calves, and we can assume that a calf is sighted during its month of birth.
Calves in Doubtful Sound are almost never born outside this 8 mo period (Haase \& Schneider 2001, Henderson et al. 2014). Although there has been some extension of home-range beyond Doubtful Sound over recent years, the population is essentially closed to immigration/emigration and all individuals have very high resighting rates, with every individual in the population typically sighted each trip (Henderson et al. 2013). Consequently, we assumed that if a female was repeatedly resighted (minimum of 10 encounters) without her calf during a monitoring trip after the calf had been first sighted, the calf had died. The identity of a calf's mother was inferred from constant close association during a minimum of 10 separate encounters over several days, of a particular female with that calf. The small size of the population ( $n=60$ at 2012) and high resighting rates allow for confidence that every reproductively active female (provided they are over 8 yr of age [see 'Mother size' below]) has been included in the analysis. Because of the long-term nature of the study, in order for a female not to be included as reproductively active, the survey team would have had to have missed multiple calf births for that female. This is very unlikely. Moreover, the sex of every adult individual in the population is known via close observation over $20+$ yr. Reproductive histories were used to assign a fate (i.e. survival to 1 and $3 \mathrm{yr}$ ), time of birth and mother ID to each calf.

\section{Mother size}

The size of female dolphins was measured in the field using a purpose-built digital stereo-photogrammetric system (Brough 2013), which is a modified version of that used to measure sperm whales (Growcott et al. 2012). The method allowed for repeated measurement of individuals to assess the degree of measurement error inherent within the system (mean $\mathrm{CV}=2.43 \%$ ). The measured distance (upper jaw to dorsal fin, UJ DF) is a good proxy for total length $\left(r^{2}=0.94\right.$, Brough 2013). Total length is a standard measurement of size in marine mammals which is closely related to total body mass (Trites \& Pauly 1998). Animal condition is likely to change from year to year (Miller et al. 2011, 2012), and thus our static (at 2012) length estimate for female dolphins is unlikely to represent a mother's breeding condition for calf births before 2012. While year-to-year breeding condition is an important factor influencing reproductive success (Miller et al. 2012), variation in absolute body size among individuals in a population 
may also be important (Reiter et al. 1981, Hussey et al. 2010). In Doubtful Sound there is substantial variation in body size among adult dolphins (Chong \& Schneider 2001, Brough 2013), providing an interesting opportunity to assess how reproductive success may be influenced by body size in a cetacean species inhabiting a harsh environment. In this population, the majority of body growth occurs during the first $8 \mathrm{yr}$ of life (Chong \& Schneider 2001). Thus, in order to ensure that the size of individual females has remained constant over the study period, calf births were excluded from the analysis if mothers could have been younger than $8 \mathrm{yr}$.

\section{Month of birth}

The long-term dataset included the dates of first and last sightings for all calves born into the population (Henderson et al. 2014). Cases in which birth month was not certain (e.g. when there was $>1$ mo between sampling trips) were not included in the analysis. Preliminary analysis of month of birth data indicated problems with model convergence when using birth month (October-April) as different levels in a categorical factor. This is likely due to there being very few observations of calf births in months other than December, January and February and the subsequent problems with data dispersion. For this reason the month of birth factor clustered data into 3 levels describing whether calves were born before January (the months October, November and December), during January, or after January (the months February, March and April). No calf births events were recorded between May and September. This clustering of birth month data is consistent with a previous study on this population that suggests January may be a 'sweet-spot' for calf survival (Henderson et al. 2014).

\section{Mother age}

Age is known directly for females born into the population since 1990. Ten of the reproductively active females in the population were, however, first observed as 'adults' ( $>3 \mathrm{yr}$ old) at the beginning of the research programme and were therefore accorded a value for minimum age in the analysis (i.e. the age value for these females was set at $3 \mathrm{yr}$ at 1990). Conceivably, these 10 females could have true ages anywhere between 3 and $50 \mathrm{yr}$, and so this decision obviously reduces our ability to assess whether the older females have reduced reproductive success. The age data distinguished between the older females and those born into the population, thus presenting an opportunity to assess if younger females are more or less successful at raising young. In some species, disparity in reproductive success due to age is most evident for young females, especially when full reproductive potential is not reached until well after age of first birth (Clutton-Brock 1984, Cameron et al. 2000). Thus, including an age parameter in this analysis that distinguishes young females was considered useful.

\section{Tailrace freshwater discharge}

Doubtful Sound is subjected to habitat modification due to the existence of a hydro-electric power station that diverts up to $550 \mathrm{~m}^{3} \mathrm{~s}^{-1}$ of freshwater from Lake Manapouri into the fiord (Bowman et al. 1999). It may be that the increased freshwater discharge from the power station affects both temperature and resources in the fiord. Such an affect could be correlated with the significant decrease in calf survival at 2002, when a second tailrace tunnel was opened (Currey et al. 2009b). The second tailrace tunnel from the Lake Manapouri hydro-electric scheme began to divert water into the Doubtful Sound complex in May 2002. In order to assess whether calf survival has decreased following the opening of the second tailrace, a binomial predictor variable was included in the modelling structure that specifies whether the second tailrace was operational (0) or not (1).

\section{Statistical approach}

This study used general linear mixed models (GLMM) to assess the range of effects contributing to variation in calf survival to $1 \mathrm{yr}$ ('S.1') or to $3 \mathrm{yr}$ ('S.3'). In Doubtful Sound, calf mortality typically occurs within the first year (usually in the first month) with an additional peak in mortality around $3 \mathrm{yr}$ of age, possibly associated with weaning (Henderson et al. 2014). Other studies assess reproductive success of mothers as raising a calf to 3 yr old only (Mann et al. 2000, Mann \& Watson-Capps 2005, Mann et al. 2008). However, as the various factors may differ in importance as calves grow, we chose to model variation in survival to both 1 and $3 \mathrm{yr}$ of age.

The GLMM framework allows for a combination of categorical, continuous and binomial data and enables the inclusion of both fixed and random effects 
(Bolker et al. 2009a, Bates et al. 2014b). Because of this flexibility, GLMMs have been widely used in ecological studies (Briceño et al. 2010, Iwasaki \& Brinkman 2015) and are becoming increasing popular for modeling survival data with random (e.g. individual level) factors (Milner et al. 1999, Vergara et al. 2007).

The model framework was based on a binary response variable of calf survival $(1=$ survived, $0=$ did not survive). There was an observation for every calf born into the population between 1995 and 2012, provided its mother was known, was still present in 2012, and the mother was over the age of $8 \mathrm{yr}$ at the time of birth (see above). Calves whose mothers had died before 2012 (n mothers $=8$ ) were not included in the study. As photogrammetric sampling was carried out in 2012, size estimates were available only for females that were alive in 2012.

Each observation of a calf survival event had associated observations of various factors. Interactions effects between parameters were excluded from the modelling framework due to issues with model convergence that were potentially a product of generating complex models with a dataset that was (unavoidably) small (Zuur et al. 2009). Mother ID was specified as a random factor ('RE') in the modelling framework.

Models were developed in the program $R$ (version 3.0.3; R Core Team 2015) using the package lme4 (version 1.1-5; Bates et al. 2014a) following a method described by Grueber et al. (2011). The glmer function of lme4 fits GLMM models by estimating model parameters via maximum likelihood (ML). ML is approximated using either Laplace approximation or Gausian-Hermite quadrature (Bolker et al. 2009a, Zuur et al. 2009). Two global models were configured, one for each response variable (S.1 and S.3), that included each input parameter as below:

$$
\begin{aligned}
& \text { S.1 } \sim \text { Size + Age + Month(factor })+ \text { Tailrace } \\
& \text { S.3 } \sim \text { Size + Age + Month(factor })+ \text { Tailrace }
\end{aligned}
$$

Mother size (Size) and mother age (Age) are discrete continuous variables, Month is a categorical factor with 3 levels and Tailrace is binomial. The models used a logit link function, binomial error distribution and Laplace approximation of ML. Model data were standardised using the centralising mean method with the standardize function in package arm (version 1.6-10; Gelman \& Su 2013). Next, full model sets containing every possible combination of input parameters were created for each global model using the dredge function in MuMIn (version 1.9.0; Barto 2015). We used an information-theoretic approach to model selection (Burnham \& Anderson 2002). Models were ranked via AICc, a modified version of Akaike's information criterion (Akaike 1973) which reduces bias for small sample sizes (Hurvich \& Tsai 1989). A 'top model' set was generated for each response that included every model having a $\triangle \mathrm{AICC}$ value of 6 or less compared to the most parsimonious model (Burnham \& Anderson 2002).

In cases in which differences among subjects are not of particular interest, random factors are often treated as 'nuisance' parameters (Bolker et al. 2009b, Iwasaki \& Brinkman 2015). In the context of this study, differences in reproductive success among female dolphins are of interest. Allowing for a RE parameter of mother ID in our modelling framework presents an opportunity to assess this. To assess the level of variation in reproductive success among female dolphins, we compared the model outputs and model selection values (AICc values and model weights) of a reduced (null) model containing only our RE parameter, with the top models for both S.1 and S.3 model sets. RE (among-subject) variation can be accounted for by variation in fixed effects (Scheipl et al. 2008, see 'Results'), which may present difficulties when using models with significant fixed effects to assess differences among RE levels. Therefore, it was necessary to use the conditional modes and unconditional standard errors from the S.1 and S.3 null models to evaluate differences in reproductive success among individual females (see Table 3). The conditional modes and unconditional error of each level within our random factor were extracted using the ranef function in package $1 m e 4$.

To assess the fit of the models to the survival data, diagnostic plots were generated to assess (1) homogeneity of variance, (2) whether data transformed by the link function were linear with respect to continuous input parameters and (3) normality of model residuals and random effects (Bolker et al. 2009a, Bolker 2015). The binomial response variable made it necessary to fit smoothed curves with confidence intervals to plots of residuals (Pearson) vs. fitted values to determine (1). This was undertaken with package qqplot2 (version 1.0.1; Wickham \& Chang 2015) using the functions qplot and stat_smooth. The same function was used to assess (2) by plotting continuous input parameters (size \& age) against the models' predicted values. A further assessment of (1) was carried out using binned residual values vs. expected model values using binnedplot in the package arm. Normality of residuals (3) was assessed 
using the function qqnorm to compare the distribution of model residuals with a normal distribution. The assumption that the random effects assume a normal distribution was also tested with qqnorm by comparing the conditional modes of the random parameter with a normal distribution. To further test residual normality Shapiro-Wilk tests (Shapiro \& Wilk 1965) were carried out on both the model residuals and RE conditional modes. Data overdispersion was assessed for both model sets by comparing residual deviance with residual degrees of freedom (Bolker 2015).

\section{Model averaging}

For model outcomes with no clear 'best' model (model weight 0.90 or over and/or $\triangle \mathrm{AICc}<2$ ), parameter estimates are more realistic when the coefficients are averaged across all models that contribute some weight, rather than relying on estimates generated from the top model only (Burnham \& Anderson 2002, Johnson \& Omland 2004).

Two main model-averaging methods have been advanced (Burnham \& Anderson 2002). The 'naturalaverage' method averages parameters and error over models in which they appear, weighting each parameter by the sum of the model weights. In contrast, the zero method averages each parameter over all models in the set, substituting a 0 value when a parameter is absent from a particular model. (Burnham \& Anderson 2002, Grueber et al. 2011). It has been suggested that the 'zero' method is more appropriate when the goal is to determine the factors that have the strongest influence on the response (Nakagawa \& Freckleton 2011). The 'natural average' method is more suited to situations in which there is a particular variable of interest may have a comparatively small effect size; thus, the shrinkage encountered with the 'zero' method is probably best avoided (Nakagawa \& Freckleton 2011).

Model averaging of parameters was carried out with the model.avg function in MuMIn using the 'zero method', because this study is concerned with determining the factors that have the strongest influence on the response (Burnham \& Anderson 2002). The size of the estimated coefficient indicates the degree to which each predictor accounts for variation in calf survival and allows the predictor variables to be ranked. We used 95\% confidence intervals to judge the significance of each parameter's predictive capacity (Burnham \& Anderson 2002, Grueber et al. 2011, Nakagawa \& Freckleton 2011). A parameter was deemed significant if its confidence interval did not include zero (Grueber et al. 2011, Nakagawa \& Freckleton 2011).

The inclusion of models in a top model set that are more complex versions of a highly ranked model may cause bias when performing model averaging (Richards 2005, 2008, Richards et al. 2011). This problem can be exacerbated with binomial datasets and can be particularly problematic with overdispersed data (Richards 2005, 2008). Judging by traditional tests, there is no indication that the data in this study were overdispersed (see 'Results'); however, we undertook further assessment of overdispersion because of the potential for it to have substantial effects on model averaging results when complex models are included in the set. Following a method suggested by Richards (2008), models that were more complex versions of higher ranked models in the set (i.e. models that were nested within a simpler model with smaller $\triangle \mathrm{AICc}$ ) were removed from the 'top model' set (Richards 2008). Model averaging was then performed on the remaining models (Smodels) and the subsequent parameter estimates compared to those produced using the entire 'top model' set. Sizeable differences in parameter estimates, or in the statistical significance of input parameters, would suggest that model averaging across a top model set may not be appropriate given the dispersion of the data (Richards 2005, 2008). Such differences could be associated with including overly complex models in the 'top model' set.

\section{RESULTS}

\section{Observations}

As of 2012, there were 19 reproductively active females in the Doubtful Sound population. These females had given birth to a total of 57 calves since 1995. Birth month of all but 2 calves was known with confidence, and 6 of these calves were born when mothers could have been $<8 \mathrm{yr}$ of age. Thus, the total sample size for analysis was 49 . Thirty-four of the 49 survived their first year, whilst 27 of 49 survived to 3 yr of age.

Photogrammetric estimates of body size were available for all mothers currently in the population. There was substantial variation in measurements of mother size with a minimum UJ DF distance of $132 \mathrm{~cm}$ and a maximum of $217 \mathrm{~cm}($ mean $=163 \mathrm{~cm})$. Data on body proportions suggest that these measurements correspond to total lengths of 219 and 
Table 1. Summary of the 'top model' set used to estimate parameters for calf survival to $1 \mathrm{yr}$. Fixed input parameters include mother size (Size), month of birth (Month), mother age (Age) and Tailrace. The null model (i.e. no fixed effects), containing the random effect of mother ID (Mother) was not included in the top model set, yet is shown in the table for comparison. This model selection table summarises the top models in terms of degrees of freedom (df), Akaikes information criterion (AICc), delta AICc ( $\triangle \mathrm{AICc}), \mathrm{AICc}$ model weight (AICc.Wt) and a cumulative weight index (Cum.Wt)

\begin{tabular}{|lcccccc|}
\hline Model & Rank & df & AICc & AAICc & AICc.Wt & Cum.Wt \\
\hline Month + Size & 1 & 5 & 54.59 & 0 & 0.34 & 0.34 \\
Size & 2 & 3 & 55.65 & 1.06 & 0.20 & 0.53 \\
Month + Tailrace + Size & 3 & 6 & 56.57 & 1.99 & 0.12 & 0.66 \\
Month + Age + Size & 4 & 6 & 56.66 & 2.07 & 0.12 & 0.78 \\
Tailrace + Size & 5 & 4 & 57.69 & 3.11 & 0.07 & 0.85 \\
Age + Size & 6 & 4 & 57.79 & 3.20 & 0.07 & 0.92 \\
Month + Tailrace + Size + Age & 7 & 7 & 59.26 & 4.68 & 0.03 & 0.95 \\
Month & 8 & 4 & 59.48 & 4.90 & 0.03 & 0.98 \\
Tailrace + Age + Size & 9 & 5 & 60.17 & 5.59 & 0.02 & 1.00 \\
Mother(null) & 12 & 2 & 61.63 & 7.05 & 0.01 & 1.00 \\
\hline
\end{tabular}

Table 2. Summary of the 'top model' set used to estimate parameters for calf survival to 3 yr. Input parameters and abbreviations as in Table 1

\begin{tabular}{|lcccccc|}
\hline Model & Rank & df & AICc & AAICc & AICc.Wt & Cum.Wt \\
\hline Month + Size & 1 & 5 & 55.9 & 0 & 0.27 & 0.27 \\
Size & 2 & 3 & 56.19 & 0.29 & 0.23 & 0.50 \\
Tailrace + Month + Size & 3 & 6 & 57.16 & 1.25 & 0.14 & 0.64 \\
Month+ Age + Size & 4 & 6 & 57.69 & 1.79 & 0.11 & 0.75 \\
Tailrace + Size & 5 & 4 & 58.02 & 2.12 & 0.09 & 0.85 \\
Age + Size & 6 & 4 & 58.11 & 2.21 & 0.09 & 0.94 \\
Tailrace + Month + Age + Size & 7 & 7 & 59.90 & 3.99 & 0.04 & 0.97 \\
Tailrace + Age + Size & 8 & 5 & 60.48 & 4.58 & 0.03 & 1.00 \\
Mother (Null) & 11 & 2 & 67.2 & 11.26 & 0.001 & 1.00 \\
\hline
\end{tabular}

$356 \mathrm{~cm}$, respectively (Brough 2013). Minimum mother age at birth ranged between 8 and 24 yr.

\section{Model fitting}

Using standardised data (Gelman 2008), S.1 and S.3 global models easily converged, as did every model produced using the dredge function. Plots of model residuals vs. fitted values showed no indication of heteroscedasticity for either model set (Tables 1 \& 2). Homogeneity of variance was also evident in plots of individual predictor parameters. The continuous predictor values of size and minimum age were both shown to be linear in relation to model predicted values, which suggests the chosen link function was appropriate (Bolker et al. 2009a). Assessing normality of model residuals and random conditional modes using qqnorm confirmed that our residuals and random ef- fects followed a normal distribution for both model sets. Residual normality was further confirmed by Shapiro-Wilk tests that provided p-values of 0.14 and $0.28(\alpha=0.05)$ for the S.1 and S.3 global models, respectively, indicating no significant departure from a normal distribution. The assumption that the random effects (see Fig. 4) approximated a normal distribution was supported for the S.3 analysis with the null (RE only) model producing a Shapiro-Wilk pvalue of $0.07(\alpha=0.05)$; however, the random conditional modes for the S.1 null model produced a Shapiro-Wilk pvalue of 0.04 , suggesting significant ( $\alpha=0.05)$ departure from a normal distribution. It has been suggested that the influence of non-normal modes is unlikely to compromise a GLMM fit except for extreme deviations from a normal distribution (Bolker 2015). The graphical representation of the S.1 conditional modes did not identify any extreme deviations from normal or outliers. Moreover, conditional modes from the S.1 global model were not significantly different from a normal distribution ( $p$-value $=0.21$ ). Thus, we assume that the slight deviation from normality for the S.1 conditional modes will not compromise our model fitting and subsequent parameter estimates (see Supplements $2 \& 3$ at www.int-res. com/articles/suppl/n029p255_supp.pdf for model diagnostic plots). Comparing residual deviance with residual degrees of freedom for both global models suggested that the data for each model set (Tables 1 \& 2) were not overdispersed.

\section{Survival to $1 \mathrm{yr}$}

The most parsimonious S.1 model (indicated by the lowest AICc value and highest weight) combined month and mother size as predictors (Table 1). Mother size featured in all but one of the top models. The second best model, in which size was the only parameter, contributed 0.20 in model weight. Month of birth in particular featured strongly, with the models containing this parameter adding to a weight of 0.64 (Table 1). All other input parameters featured in the top S.1 models. 


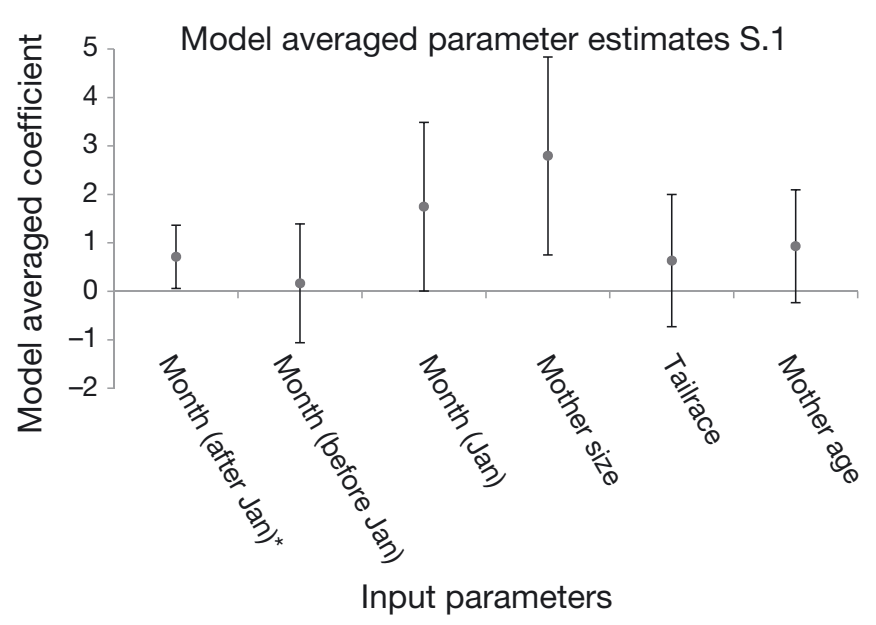

Fig. 2. Model averaged estimates of the contribution of predictor variables to variation in calf survival to $1 \mathrm{yr}$. Average coefficient values reflect magnitude of effects. Error bars reflect $95 \%$ confidence intervals using unconditional standard error. Parameter estimates are on the scale of the standardised linear predictor variables. ${ }^{*}$ : level of the categorical month factor that was used as the intercept for the model; all other levels of the month factor are compared to this reference category $\mathrm{CI}$

Although a 'best' model was selected, it did not have a model weight $>0.9$, and the second, third and fourth models contributed a reasonable amount to the cumulative weight index (Table 1). This indicates that no single model adequately explains variation in survival to $1 \mathrm{yr}$ and confirms the utility of using model averaging to produce parameter estimations.

Calf survival to $1 \mathrm{yr}$ was significantly affected by month of birth and mother size (as indicated by $95 \%$ confidence intervals that did not overlap 0; Fig. 2). A positive coefficient of 1.75 indicates that calves born in January had a higher chance of survival. Moreover, it seems that calves born after January were also more likely to survive to $1 \mathrm{yr}$, although this effect is smaller (coefficient 0.71; Fig. 2). Model averaged parameter estimates of the various factoral 'Month' levels were relative as the level 'after Jan' was selected as the intercept for model fitting. Mother size was the best predictor of survival to $1 \mathrm{yr}$ with a positive model-averaged coefficient of 2.79 . The additional parameters - tailrace and minimum mother age - were not shown to be important predictors of calf survival to 1 yr (Fig. 2).

\section{Survival to 3 yr}

Models included in the top model set for the S.3 analysis were almost identical to those featuring in

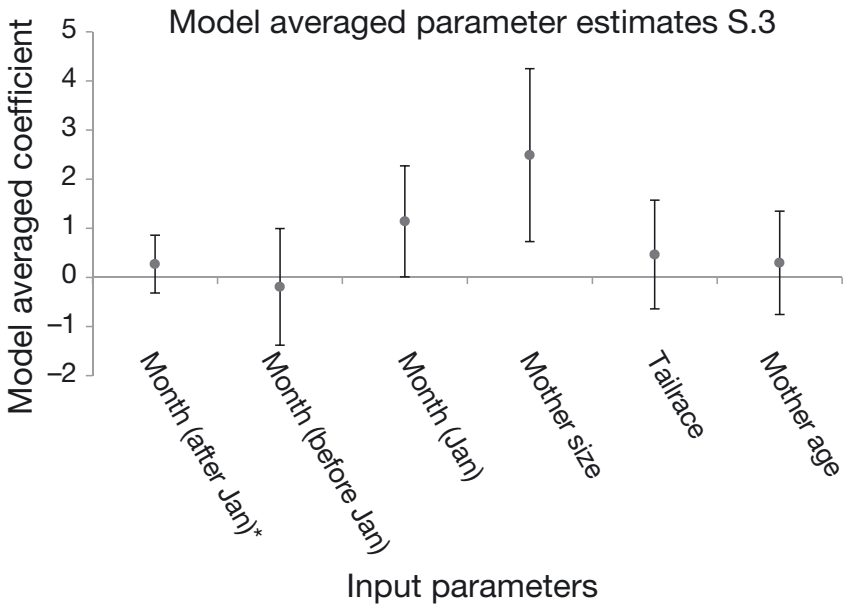

Fig. 3. Model averaged estimates of the contribution of predictor variables to variation in calf survival to $3 \mathrm{yr}$. Other details as in Fig. 2

the S.1 top model set (Table 2). As in the S.1 analysis, the best model predicting survival to $3 \mathrm{yr}$ combined month and mother size (Table 2). Both month and mother size featured strongly in the top model set, with a size-only model occupying the 2 nd rank of the model set, and contributing 0.23 in model weight (Table 2). Unlike the top model set for the S.1 analysis, a month-only model was not included in the top model set for S.3. Similar to the model outputs for survival to $1 \mathrm{yr}$, the best model in the $\mathrm{S} .3$ analysis did not have a model weight $>0.9$, indicating there was no one model that adequately described the variation in survival to 3 yr (Table 2).

Both mother size and month parameters were significant in predicting calf survival to 3 yr (Fig. 3). As for the S.1 analysis, model averaged parameter estimates of the various factoral 'Month' levels are relative, as the level 'after Jan' was selected as the intercept for model fitting. Tailrace and minimum mother age had positive mean values but their confidence intervals overlapped zero. Mother size had the highest model-averaged coefficient at 2.49. The only level of the month parameter with a significant effect on calf survival to $3 \mathrm{yr}$ was January, with a modelaveraged coefficient of 1.14 (Fig. 3).

\section{Random effects}

The influence of mother ID was slightly different for each model set (Table 3). In the S.1 analysis, the null model indicated strong variation in the conditional modes among individual females (Fig. 4). The overall model variance associated with the S.1 ran- 


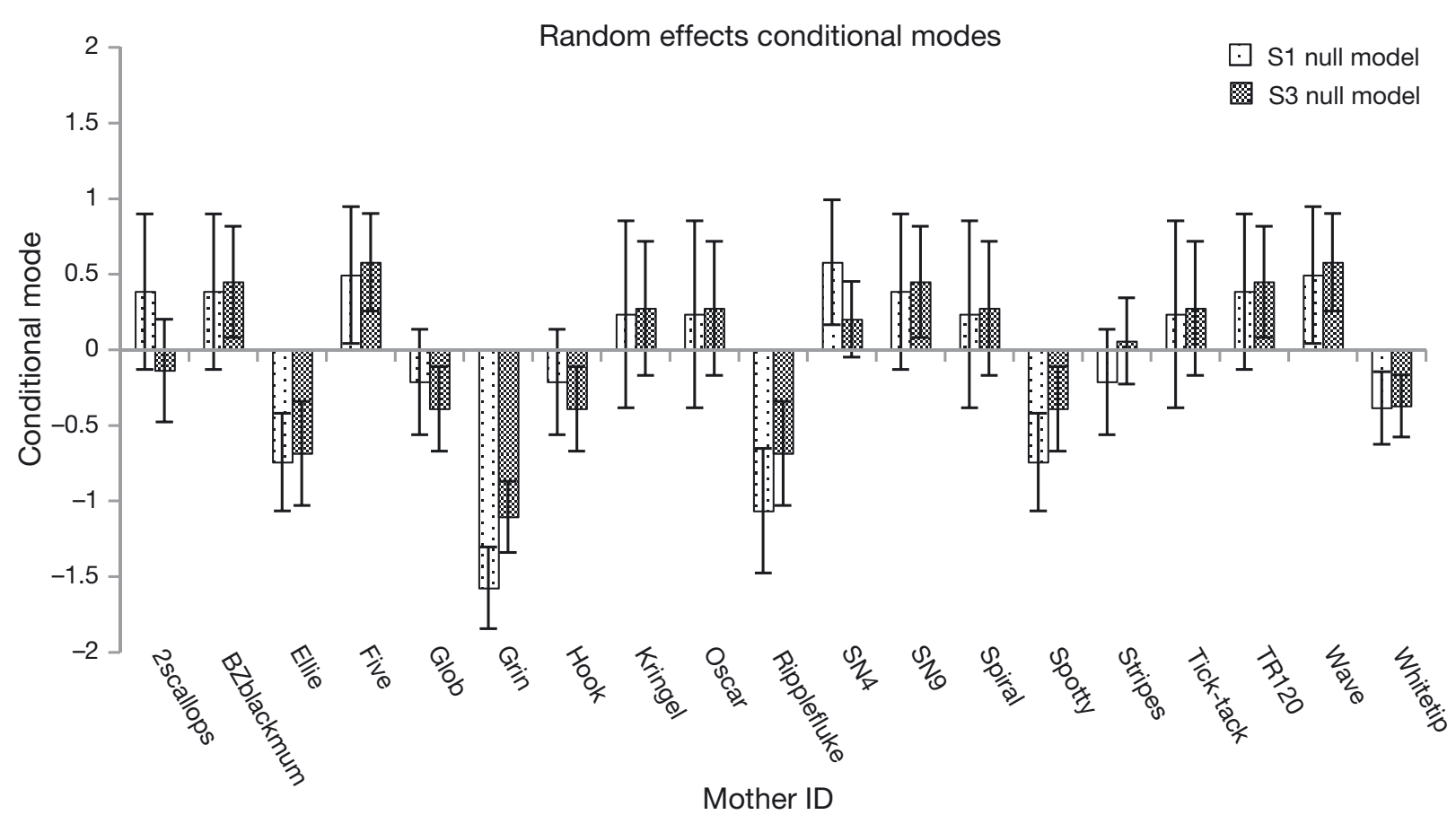

Fig. 4. Conditional modes for the random effect of mother ID for the survival to 1 and 3 yr null models. Error bars are \pm unconditional standard error

dom parameter was 0.84 for the null model. This variance was reduced for the S.1 global model (0.81) and top model $(0.70$; Table 3$)$. This suggests that some among-individual variance in reproductive success is not accounted for by the fixed factors in the S.1 analysis. However, the S.1 null model occupied a low 12th rank in the overall model set and was not included in the top model set when ranked by AICc (Table 1).

The conditional modes from the S.3 null model suggest considerable variation among mothers in terms of calf survival to $3 \mathrm{yr}$ (Fig. 2). This is further confirmed by overall model variation attributable to the S.3 null model random parameter of 0.591 (Table 3). The variance associated with the random parameter

Table 3. Variance associated with the random effects of mother ID for the null, global and top models for the survival to 1 (S.1) and 3 (S.3) yr analysis

\begin{tabular}{|lc|}
\hline Model & Random variance \\
\hline Null S.1 & 0.84 \\
Global model S.1 & 0.82 \\
Top model S.1 & 0.7 \\
Null S.3 & 0.59 \\
Global model S.3 & 0 \\
Top model S.3 & 0 \\
\hline
\end{tabular}

for the S.3 global and top models was 0. This suggests that for the S. 3 analysis the total among group variance was accounted for by variation in the fixed factors. The S.3 null model also occupied a low position (11th) in the model selection table, contributing almost zero weight to the overall model set, and was not included in the top model set (Table 2). The low position of the S. 3 null model and the 0 random variance term for the $\mathrm{S} .3$ global and top models suggests that variation in reproductive success among females is reduced when the fixed factors are taken into consideration (Tables $2 \& 3$ ). That being said, it is still important to assess where differences in reproductive success exist; thus, the null model has been used to illustrate these differences (Fig. 4).

\section{Top model set vs. simple models}

Using a simplifying rule to exclude complex models from the sets used for model averaging (Richards 2005,2008 ) reduced the number of parameters for which estimates were available (Table 4). The simplifying rule made no difference to the parameters deemed to be statistically significant. Moreover, parameter estimates generated using the entire top model set were very similar to those from the simplified model set (Table 4). This indicated that model 
averaging of input parameters across our top models sets was appropriate given the level of dispersion in our binomial response variable. That similar parameter estimates were produced using the top model and the stricter 'Smodel' set provides further validation of our results, as we arrived at the same conclusion using the 2 different model averaging methods.

\section{DISCUSSION}

\section{Modelling}

Using a mixed modelling approach combined with model averaging proved useful for unravelling the relative importance of the various predictor variables. However, there is often some bias associated with calf survival data due to unobserved birth events. Over the course of the study it is likely that some calving events were not documented (i.e. when a calf died shortly after birth). This problem is well recognised in other studies of calf survival in marine mammals (Mann et al. 2000, Kogi et al. 2004, Currey et al. 2009b). Failure to record a calving event in which the calf had died soon after birth would cause calf survival rates to be biased high. In contrast, overall calf production per year would be biased low (Henderson et al. 2014). In the present study, we assume that these biases will not influence model outcomes and subsequent parameter estimates. This assumption is reasonable as it is likely only a very small number of births attributable to the females in this study were missed. Tour operators in daily direct contact with the dolphins noted only 3 'potential' births (followed by early mortality) that the monitoring team were unaware of. Seventy-four births were recorded between 1995 and 2012 (not all of these were included in the analysis as above). We consider 3 potentially missed births to be a sufficiently small proportion such that it would not affect our model outcomes, particularly as these birth events are by no means certain and may not have been attributable to the females in this study. In any case, these births were not included in the present study because it was not possible to establish the mothers' identities.

Our exclusion of any mothers that could have been younger than $8 \mathrm{yr}$ old minimised the likelihood of mother size changing significantly over the study period, as growth should have reached an assymp- tote by that age. Nevertheless, some mothers in this study are likely to have been smaller in the past than the measurement made at 2012. Not all bottlenose dolphins reach maximum size at the same age (Read et al. 1993), and thus it is possible some of the mothers born into the population between 1990 and 2012 would have continued to grow past 8 yr of age. Females often reach asymptotic length before males (Read et al. 1993), and Kerem et al. (2013) have shown that $99 \%$ of growth in female bottlenose dolphin occurs before $6 \mathrm{yr}$. Additionally, growth rates slow dramatically as dolphins approach asymptotic length (Read et al. 1993, Chong \& Schneider 2001). Hence, any increases in mother size over the study are likely to be negligible.

\section{Individual heterogeneity}

Interpretation of the conditional modes and RE variance from the S.1 and S.3 models sets confirms that mothers in the Doubtful Sound population show considerable variation in reproductive success (Fig. 4). There is good correlation between the magnitude of the RE conditional modes and the calving histories for individual females. For example, since 1995 the females Grin, Ellie and Ripplefluke have, between them, not had a single calf survive to $3 \mathrm{yr}$ and are represented with the largest negative conditional modes (Fig. 4). A similar but reverse pattern is observed for the most successful mothers SN4, Wave, Five and BZblackmum (Fig. 4).

Slightly more variation in calf survival was attributable to REs in the S.1 than the S.3 analysis (Table 3). This suggests that reproductive heterogeneity was 
stronger in first year calf survival. The top model for the S.1 analysis still retained some variance associated with the random factor, demonstrating that not all variability in first year calf survival can be accounted for by the fixed effects. In contrast, RE variance for the S.3 analysis was effectively zero, suggesting that survival to $3 \mathrm{yr}$ was completely accounted for by the fixed effects parameters. It has been discussed that zero RE variance may represent model over-fitting (Bolker 2015), which may bias random slope estimates for strongly unbalanced designs (Schielzeth \& Forstmeier 2009). However, because of the binary response in our modelling framework, the zero RE variance estimate is likely to be consistent with a pure Bernoulli process with conditioning on the covariates.

Variability in reproductive success among individual bottlenose dolphin females has also been demonstrated in Shark Bay, Australia, where it has been attributed to inbreeding (Frère et al. 2010) and particular patterns of habitat use (Mann et al. 2000). Fruet et al. (2015) showed strong variation in female reproductive success in a bottlenose population in Brazil, where, as in Doubtful Sound, some individuals have never had a calf survive to 3 yr. High variance in reproductive success seems likely to be a feature of many dolphin populations.

\section{Mother size}

Calf survival to 1 and 3 yr was best explained by the size of the mother, with larger mothers being more successful (Figs. 2 \& 3). Mother size is often correlated with her overall condition and reproductive fitness (Fairbanks \& McGuire 1995, Derocher \& Stirling 1998). In this study, as mother size was measured as length, and only in 2012; it does not accurately represent breeding condition, which is likely to change over time (Miller et al. 2011, 2012). Yet, the fact that variation in absolute body size among female dolphins in Doubtful Sound influences calf survival is an interesting and important result. Three main hypotheses have been advanced to explain how large female size may enhance the survival of offspring in mammals:

(1) Larger females may retain a higher position in the social hierarchy, presenting better opportunities to breed and potentially increasing exposure to top ranked males of superior fitness (Reiter et al. 1981, Wauters \& Dhondt 1989).

(2) Larger females may give birth to larger offspring that are more capable of surviving the first years in a challenging environment (Atkinson \& Ramsay 1995, Derocher \& Stirling 1998).

(3) The energetic requirements of lactation are a significant tax upon the resources of mammalian mothers (Stewart \& Lavigne 1984, Miller et al. 2012). If larger mothers have more resources, they may provide better quality and/or quantity of milk to their young, maximising chances of growth and survival (Iverson et al. 1993, Sakai \& Harada 2001). However the opposite could also be true. Smaller mothers, not being required to support a large body size, may have greater resources available for the rearing of young (Pomeroy et al. 1999).

Bottlenose dolphins have a promiscuous mating system, with frequent mating (Scott et al. 1990, Whitehead \& Mann 2000). In this context, the first hypothesis seems unlikely to be true. Hypotheses 2 and 3, however, seem to have more merit. In this study we were unable to assess whether larger females give birth to larger calves because photogrammetric sampling was carried out during 2012 and so was limited to the calves of that year only. For species inhabiting temperate and polar regions where food supply is variable and climatic conditions extreme, the benefits of maintaining a large body size for maximising reproductive success are likely to be important (Sand 1996, Derocher \& Stirling 1998, Miller et al. 2012). Especially in marginal habitats, it may be that smaller females have fewer resources available to contribute to offspring (Sand 1996). It has also been suggested that smaller females may retain resources for themselves, sacrificing maternal investment to favour their own survival and potential for future reproduction (Fairbanks \& McGuire 1995, Festa-Bianchet \& Jorgenson 1998). In bighorn sheep this trend is particularly evident during periods of resource scarcity (Festa-Bianchet \& Jorgenson 1998). As mother size had a significant influence on calf survival outcomes to both 1 and 3 years of age (Figs. 2 \& $3)$, there is no evidence that large mother size benefits particular calf age classes in different ways.

\section{Birth timing}

Survival to 1 and $3 \mathrm{yr}$ also seems to be strongly affected by the calf being born at particular times during the calving season (Figs. $2 \& 3$ ). Survival of calves to 1 yr was significantly predicted by being born during and after January, whilst January was the only significant month of birth level predicting survival to 3 yr. This suggests that calves born during and after January have a higher chance of survival 
relative to calves born during other periods. This trend was first identified in Doubtful Sound by Henderson et al. (2014), who showed that the 6 most successful mothers gave birth to a higher proportion $(53 \%)$ of their surviving calves in January. The present study has confirmed this trend via statistical modelling of month of birth along with other potential predictor variables (Fig. 2).

Seasonal reproduction is the norm in a wide range of taxa including ungulates (Festa-Bianchet 1988, Gaillard et al. 1997), birds (Phillips et al. 1996, Vergara et al. 2007), reptiles (Moore et al. 1984) as well as marine mammals (Chittleborough 1958, Majluf 1992). Generally, bottlenose dolphin populations show narrow calving seasons at high latitudes (Mann et al. 2000, Haase \& Schneider 2001), and broader calving seasons at low latitudes (Scott et al. 1990, Urian et al. 1996). Seasonal reproduction may have evolved to reduce climatic stresses upon offspring (Ims 1990, Ransome \& McOwat 1994) and/or to take advantage of seasonally abundant resources for raising offspring (Daan et al. 1988, Goldizen et al. 1988). There are substantial seasonal fluctuations in water temperature and salinity within the Doubtful Sound complex (Gibbs et al. 2000). Moreover, cool water temperatures can persist well into the calving season as rainstorm events and cold fronts can cause dramatic decreases in water temperature (Gibbs et al. 2000). Cool water temperatures are likely to cause thermal stress to smaller, thinly insulated calves (Yeates \& Houser 2008), a fact that may explain why calves that die in their first year typically die in the first month (Henderson et al. 2014).

It is possible that food resources within the fiord are seasonally limited, influencing the optimal timing for giving birth. Primary productivity in the New Zealand fiords is low due to low sunlight, limited space for macroalgae and high fluctuations in temperature and salinity (Peake et al. 2001, Tallis et al. 2004). Previous research has identified that dolphins in Doubtful Sound are more reliant on demersal, reef-dwelling prey species than on a seasonal influx of pelagic species (Lusseau \& Wing 2006). Studies of other populations of bottlenose dolphins have linked seasonal reproduction to the availability of seasonal resources (Urian et al. 1996, Fruet et al. 2015). It may be that although pelagic species do not constitute a significant proportion of dolphin diet in Doubtful Sound, they are seasonally important for pregnant/lactating females during the calving season. Large schools of mackerel (Scomber australasicus and Trachurus declivis) can occur in the fiord during late spring and early summer (T. E. Brough pers obs.); thus, it is possi- ble that the optimal January calving window is a trade-off between seasonally abundant resources during early summer (November/December) and the warmest water temperatures (February). Mean monthly temperature at birth was originally included in the analysis as a covariate but was subsequently excluded due to a correlation with month of birth.

Fruet et al. (2015) assessed female reproductive traits and success in a population of bottlenose dolphins inhabiting the sub-tropical southwest Atlantic. Substantial heterogeneity in female reproductive success was evident as was a narrow temporal 'pulse' for calf births during the calving season. It was suggested that the pulse in calf births may be related to warmer water temperatures and increased dolphin prey availability, which may favour calf survival during the pulse period. No evidence was provided to support this hypothesis, however.

There is some evidence for inter-annual variability in calf survival in this population (Currey et al. 2009b, Henderson 2013). Year-to-year variation in calf survival was not assessed in this study due to issues with the parameterisation of 'year' as a factor and subsequent problems with quasi- or complete separation (Abrahantes Cortińas \& Aerts 2012). Inter-annual variability in calf survival will be the focus of further study on this population (T. E. Brough et al. unpubl.).

\section{Tailrace}

The increase in freshwater inflow to the fiord system from the Manapouri hydro-electric scheme has caused the fiord's low salinity layer to become deeper and colder at certain times of the year (Gibbs et al. 2000, Peake et al. 2001) and has dramatically altered some biological communities with the fiord (Tallis et al. 2004, Rutger \& Wing 2006). These effects were most evident when the tailrace opened in 1971. The inclusion of a tailrace parameter, denoting the presence or absence of the second tailrace tunnel and its potential effects, was not shown to have a significant influence on calf survival in this study (Figs. $2 \& 3$ ). Due to the complicated relationship between the dolphins, their habitat and the tailrace, it may be that a binomial tailrace parameter was too simplistic to accurately describe variation in calf survival.

\section{Mother age}

Minimum mother age was not shown to be a significant predictor of calf survival to 1 or $3 \mathrm{yr}$ (Figs. 2 
\& 3). Lack of accuracy in our parameterisation of age (i.e. underestimated age for females that were observed as adults at 1990) may have impacted our ability to establish age-related effects. Increasing age or experience may allow a mother to target her care towards her offspring at times when it is most needed (i.e. cooler temperatures; Green 1993, Cameron et al. 2000). This is the 'targeted care hypothesis', which proposes that while total reproductive effort may not increase with age, a mother's ability to recognise important timing for application of maternal care may (Cameron et al. 2000). For long-lived species living in an extreme environment, such as the dolphins of Doubtful Sound, such application of maternal care may increase substantially a calf's chances of survival. Age has been correlated with reproductive success in other bottlenose populations (Frère et al. 2010, 2015). As population monitoring continues in Doubtful Sound, age-related effects upon reproduction may be better determined in the future.

\section{CONCLUSIONS}

This study reveals how females within marine mammal populations can contribute unequally to the reproductive rate of the population, based on biological factors. In Doubtful Sound, heterogeneity in female reproductive success is attributable to larger mothers being more successful and the ability of females to give birth at the optimum time. These results further confirm that variable female reproductive success, in terms of calf survival, is the primary cause of vulnerability in this population. Future management of the population should focus on protecting vulnerable demographic groups. In particular, management could prevent or minimise future impacts that could influence the 'sweet-spot' in birth timing (i.e. alteration of environmental conditions) or minimise disturbance to calves during this time from tourism operations. These findings may also be important in an evolutionary context. It is well established that the bottlenose dolphins found at high latitudes are larger than those in warmer waters (Chong \& Schneider 2001). Large mothers having higher reproductive success may well be the mechanism driving this phenomenon. For threatened populations or species that are limited by neonatal or juvenile survival, understanding the mechanisms that influence reproductive heterogeneity may prove crucial in developing management strategies to target anthropogenic contributions to vulnerability.
Acknowledgements. Firstly, we thank the numerous people that have contributed to the Doubtful Sound bottlenose dolphin photo identification dataset over the years: Jamie Williams, Karsten Schneider, Patti Haase, David Lusseau, Lucy Rowe, and Rohan Currey. This project was made possible via funding from the NZ Whale and Dolphin Trust, NZ Department of Conservation and the University of Otago. The team at the Fiordland district office of the Department of Conservation have been invaluable to this project in the last decade. We particularly thank Dave Johnson, Richard Kinsey, Pete Young and Dallas McHardy. Thanks to Real Journeys Ltd. and Deep Cove education trust for transport and accommodation in the field.

\section{LITERATURE CITED}

Abrahantes Cortińas J, Aerts M (2012) A solution for separation of clustered binary data. Stat Model 12:3-27

Akaike H (1973) Information theory and an extension of the maximum likelihood principle In: Csáki F (ed) 2nd International Symposium on Information Theory. Akadémiai Kiadó, Budapest, p 267-281

Andrén H (1990) Despotic distribution, unequal reproductive success, and population regulation in the Jay Garrulus Glandarius L. Ecology 71:1796-1803

Atkinson SN, Ramsay MA (1995) The effects of prolonged fasting of the body composition and reproductive success of female polar bears (Ursus maritimus). Funct Ecol 9: 559-567

Baker JD, Polovina JJ, Howell EA (2007) Effect of variable oceanographic productivity on the survival of an upper trophic level predator, the Hawaiian monk seal Monachus schauinslandi. Mar Ecol Prog Ser 346:277-283

Barto K (2015) MuMIn: multi-model inference. R package, version 1.14. http://r-forge.r-project.org/projects/mumin/

Bates D, Maechler M, Bolker B, Walker S (2014a) Package 'Lme4', linear mixed effects models using Eigen and S4. http://lme4.r-forge.r-project.org/

Bates D, Mähler M, Bolker B, Walker S (2015) Fitting linear mixed-effects models using lme4. J Stat Soft 67, doi: 10.18637/jss.v067.i01

> Berger J (2012) Estimation of body size traits by photogrammetry in large mammals to inform conservation. Conserv Biol 26:769-777

Bolker BM (2015) Linear and general linear mixed models. In: Fox GA, Negrete-Yankelevich S, Sosa VJ (eds) Ecological statistics contemporary theory and application. Oxford University Press, Oxford, p 309-334

Bolker BM, Brooks ME, Clark CJ, Geange SW, Poulsen JR, Stevens MHH, White JSS (2009a) Generalized linear mixed models: a practical guide for ecology and evolution. Trends Ecol Evol 24:127-135

Bolker BM, Brooks ME, Clark CJ, Geange SW, Poulsen JR, Stevens MHH, White JSS (2009b) Glmms in action: geneby-environment interaction in total fruit production of wild populations of arabidopsis thaliana, revised version, part 1. http://glmm.wdfiles.com/local-files/examples/ Banta_2011_part1.pdf

Bowman MJ, Dietrich DE, Mladenov P (1999) Predictions of circulation and mixing in Doubtful Sound, arising from variations in runoff and discharge from the Manapouri power station. In: Moores CNK (ed) Coastal and ocean prediction. Coastal and Estuarine Studies. American Geophysical Union, Washington, DC, p 59-76 
Briceño F, Mascarò M, Rosas C (2010) Glmm-based modelling of growth in juvenile octopus maya siblings: Does growth depend on initial size? ICES J Mar Sci 67: 1509-1516

Brough TE (2013) Using photography to study the conservation biology of bottlenose dolphins in southern New Zealand. MSc thesis, University of Otago, Dunedin

Burnham KP, Anderson DR (2002) Model selection and multimodel inference: a practical information-theoretic approach, 2nd edn. Springer, Berlin

Cameron EZ, Linklater WL, Stafford KJ, Minot EO (2000) Aging and improving reproductive success in horses: Declining residual reproductive value or just older and wiser? Behav Ecol Sociobiol 47:243-249

$>$ Chastel O, Weimerskirch H, Jouventin P (1995) Influence of body condition on reproductive decision and reproductive success in the blue petrel. Auk 112:964-972

> Chittleborough RG (1958) The breeding cycle of the female humpback whale, Megaptera nodosa (bonnaterre). Mar Freshw Res 9:1-18

Chong AK, Schneider K (2001) Two-medium photogrammetry for bottlenose dolphin studies. Photogramm Eng Remote Sensing 67:621-628

Clutton-Brock TH (1984) Reproductive effort and terminal investment in iteroparous animals. Am Nat 123:212-229

Côtè SD, Festa-Bianchet M (2001) Reproductive success in female mountain goats: the influence of age and social rank. Anim Behav 62:173-181

Craig MP, Ragen TJ (1999) Body size, survival, and decline of juvenile Hawaiian monk seals, monachus schauinslandi. Mar Mamm Sci 15:786-809

Currey RJC, Dawson SM, Slooten E (2007) New abundance estimates suggest doubtful sound bottlenose dolphins are declining. Pac Conserv Biol 13:274-282

Currey RJC, Dawson SM, Slooten E (2009a) An approach for regional threat assessment under IUCN Red List criteria that is robust to uncertainty: the Fiordland bottlenose dolphins are critically endangered. Biol Conserv 142: 1570-1579

Currey RJC, Dawson SM, Slooten E, Schneider K and others (2009b) Survival rates for a declining population of bottlenose dolphins in Doubtful Sound, New Zealand: an information theoretic approach to assessing the role of human impacts. Aquat Conserv 19:658-670

Daan S, Dijkstra C, Drent R, Meijer T (1988) Food supply and the annual timing of avian reproduction Proc Int Ornithol Congr 19:392-407

Dawson SM, Chessum CJ, Hunt PJ, Slooten E (1995) An inexpensive stereophotographic technique to measure sperm whales from small boats. Rep Int Whaling Comm 45:431-436

Derocher AE, Stirling I (1998) Maternal investment and factors affecting offspring size in polar bears (Ursus maritimus). J Zool (Lond) 245:253-260

- Elwen SH, Best PB (2004) Female southern right whales Eubalanena australis: Are there reproductive benefits associated with their coastal distribution off South Africa? Mar Ecol Prog Ser 269:289-295

Fairbanks LA, McGuire MT (1995) Maternal condition and the quality of maternal care in vervet monkeys. Behaviour 132:733-754

Festa-Bianchet M (1988) Birth date and survival in bighorn lambs (Ovis canadensis). J Zool 214:653-661

Festa-Bianchet M, Jorgenson JT (1998) Selfish mothers: reproductive expenditure and resource availability in bighorn ewes. Behav Ecol 9:144-150

Frère $\mathrm{ClH}$, Krätzen $\mathrm{M}$, Kopps AM, Ward P, Mann J, Sherwin WB (2010) Inbreeding tolerance and fitness costs in wild bottlenose dolphins. Proc Biol Sci 277:2667-2673

> Fruet PF, Genoves RC, Möller LM, Botta S, Secchi ER (2015) Using mark-recapture and stranding data to estimate reproductive traits in female bottlenose dolphins (Tursiops truncatus) of the southwestern Atlantic ocean. Mar Biol 162:661-673

> Gaillard JM, Boutin JM, Delorme D, Van Laere G, Duncan P, Lebreton JD (1997) Early survival in roe deer, causes and consequence of cohort variation in two contrasting populations. Oecologia 112:502-513

> Gelman A (2008) Scaling regression inputs by diving by two standard deviations. Stat Med 27:2865-2873

Gelman A, Su YS (2013) Package 'arm', data analysis using regression and multilevel/hierarchical models. http:// CRAN.R-project.org/package $=$ arm

Gibbs MT, Bowman MJ, Dietrich DE (2000) Maintenance of near-surface stratification in Doubtful Sound, a New Zealand fjord. Estuar Coast Shelf Sci 51:683-704

Goldizen AW, Terborgh J, Cornejo F, Porras DT, Evans R (1988) Seasonal food shortage, weight loss, and the timing of births in saddle-back tamarins (Saguinus fuscicollis). J Anim Ecol 57:893-901

Green WCH (1993) Social effects of maternal age and experience in bison: pre- and post-weaning contact maintenance with daughters. Ethology 93:146-160

Growcott A, Sirguey P, Dawson SM (2012) Development and assessment of a digital stereo photogrammetric system to measure cetaceans at sea. Photogramm Eng Remote Sensing 78:237-246

> Grueber CE, Nakagawa S, Laws RJ, Jamieson IG (2011) Multimodel inference in ecology and evolution: challenges and solutions. J Evol Biol 24:699-711

Haase PA, Schneider K (2001) Birth demographics of bottlenose dolphins, Tursiops truncatus, in Doubtful Sound, Fiordland, New Zealand-preliminary findings. NZ J Mar Freshw Res 35:675-680

Henderson SD (2013) Habitat use, reproduction and survival: a comparative study of bottlenose dolphins in Doubtful and Dusky sounds. PhD thesis, Univeristy of Otago, Dunedin

> Henderson SD, Dawson SM, Rayment W, Currey RJC (2013) Are the 'resident' dolphins of Doubtful Sound becoming less resident? Endang Species Res 20:99-107

Henderson SD, Dawson SM, Currey RJ, Lusseau D, Schneider K (2014) Reproduction, birth seasonality and calf survival of bottlenose dolphins in Doubtful Sound, New Zealand. Mar Mamm Sci 30:1067-1080

> Hurvich CM, Tsai CL (1989) Regression and time series model selection in small samples. Biometrika 76 : 297-307

Hussey NE, Wintner SP, Dudley SFJ, Cliff G, Cocks DT, MacNeil MA (2010) Maternal investment and sizespecific reproductive output in carcharhinid sharks. J Anim Ecol 79:184-193

> Ims RA (1990) The ecology and evolution of reproductive synchrony. Trends Ecol Evol 5:135-140

Iverson SJ, Bowen WD, Boness DJ, Oftedal OT (1993) The effect of maternal size and milk energy output on pup growth in grey seals (Halichoerus grypus). Physiol Zool 66:61-88

Iwasaki Y, Brinkman SF (2015) Application of a generalized linear mixed model to analyze mixture toxicity: survival 
of brown trout affected by copper and zinc. Environ Toxicol Chem 34:816-820

Johnson JB, Omland KS (2004) Model selection in ecology and evolution. Trends Ecol Evol 19:101-108

Kendall BE, Fox GA (2002) Variation among individuals and reduced demographic stochasticity. Conserv Biol 16: 109-116

> Kerem D, Kent R, Roditi-Elasa M, Goffman O, Scheinin A, Gol'din P (2013) Early physical maturation of female common bottlenose dolphin Tursiops truncates in the eastern Levantine Basin. Isr J Ecol \& Evol 59: $154-162$

> Kogi K, Hishii T, Imamura A, Iwatani T, Dudzinski KM (2004) Demographic parameters of Indo-Pacific bottlenose dolphins (Tursiops aduncus) around Mikura Island, Japan. Mar Mamm Sci 20:510-526

> Lusseau SM, Wing SR (2006) Importance of local production versus pelagic subsidies in the diet of an isolated population of bottlenose dolphins Tursiops sp. Mar Ecol Prog Ser 321:283-293

Majluf P (1992) Timing of births and juvenile mortality in the South American fur seal in Peru. J Zool (Lond) 227: 367-383

Mann J, Watson-Capps JJ (2005) Surviving at sea: ecological and behavioural predictors of calf mortality in Indian Ocean bottlenose dolphins (Tursiops sp.). Anim Behav 69:899-909

> Mann J, Connor RC, Barre LM, Heithaus MR (2000) Female reproductive success in bottlenose dolphins (Tursiops sp.): life history, habitat, provisioning, and group-size effects. Behav Ecol 11:210-219

Mann J, Sargeant BL, Watson-Capps JJ, Gibson QA, Heithaus MR, Connor RC, Patterson E (2008) Why do dolphins carry sponges? PLoS ONE 3:e3868

McGregor KP, Krebs JR, Perrins CM (1981) Song repertoires and lifetime reproductive success in the great tit (Parus major). Am Nat 118:149-159

> Melbourne BA, Hastings A (2008) Extinction risk depends strongly on factors contributing to stochasticity. Nature 454:100-103

> Miller CA, Reeb D, Best PB, Knowlton AR, Brown MW, Moore MJ (2011) Blubber thickness in right whales Eubalaena glacialis and Eubalaena australis related with reproduction, life history status and prey abundance. Mar Ecol Prog Ser 438:267-283

Miller CA, Best PB, Perryman WL, Baumgartner MF, Moore MJ (2012) Body shape changes associated with reproductive status, nutritive condition and growth in right whales Eubalaena glacialis and E. australis. Mar Ecol Prog Ser 459:135-156

> Milner JM, Elston DA, Albon SD (1999) Estimating the contributions of population density and climatic fluctuations to interannual variation in survival of soay sheep. J Anim Ecol 68:1235-1247

Moore MC, Whittier JM, Crews D (1984) Environmental control of seasonal reproduction in a parthenogenetic lizard (Cnemidophorus uniparens). Physiol Zool 57: 544-549

Nakagawa S, Freckleton RP (2011) Model averaging, missing data and multiple imputation: a case study for behavioural ecology. Behav Ecol Sociobiol 65:103-116

Peake BM, Walls DJ, Gibbs MT (2001) Spatial variations in the levels of nutrients, chlorophyll $a$, and dissolved oxygen in summer and winter in Doubtful Sound, New Zealand. NZ J Mar Freshw Res 35:681-694
Phillips RA, Caldow RWG, Furness RW (1996) The influence of food availability on the breeding effort and reproductive success of Arctic Skuas Stercorarius parasiticus. Ibis 138:410-419

Pomeroy PP, Fedak MA, Rothery P, Anderson S (1999) Consequences of maternal size for reproductive expenditure and pupping success of grey seals at North Rona, Scotland. J Anim Ecol 68:235-253

R Core Team (2015) R: a language and environment for statistical computing. R Foundation for Statistical Computing, Vienna. www.r-project.org.

> Ransome RD, McOwat TP (1994) Birth timing and population changes in greater horseshoe bat colonies (Rhinolophus ferrumequinum) are synchronized by climatic temperature. Zool J Linn Soc 112:337-351

Read AJ, Wells RS, Hohn AA, Scott MD (1993) Patterns of growth in wild bottlenose dolphins, Tursiops truncatus. J Zool (Lond) 231:107-123

Reiter J, Panken KJ, Le Boeuf BJ (1981) Female competition and reproductive success in northern elephant seals. Anim Behav 29:670-687

Richards SA (2005) Testing ecological theory using the information-theoretic approach: examples and cautionary results. Ecology 86:2805-2814

- Richards SA (2008) Dealing with overdispersed count data in applied ecology. J Appl Ecol 45:218-227

> Richards SA, Whittingham MJ, Stephens PA (2011) Model selection and model averaging in behavioural ecology: the utility of the IT-AIC framework. Behav Ecol Sociobiol 65:77-89

Riedman ML, Estes JA, Staedler MM, Giles AA, Carlson DR (1994) Breeding patterns and reproductive success of California sea otters. J Wildl Manag 58:391-399

Rutger SM, Wing SR (2006) Effects of freshwater input on shallow-water infaunal communities in Doubtful Sound, New Zealand. Mar Ecol Prog Ser 314:35-47

> Sand HK (1996) Life history patterns in female moose (Alces alces): the relationship between age, body size, fecundity and environmental conditions. Oecologia 106:212-220

Sakai S, Harada Y (2001) Why do large mothers produce large offspring? Theory and a test. Am Nat 157: 348-359

Scheipl F, Greven S, Küchenhoff H (2008) Size and power of tests for a zero random effect variance or polynomial regression in additive and linear mixed models. Computat Stat Dat Anal 52:3283-3299

Schielzeth H, Forstmeier W (2009) Conclusions beyond support: overconfident estimates in mixed models. Behav Ecol 20:416-420

Scott M, Wells R, Irvine A (1990) A long-term study of bottlenose dolphins on the west coast of Florida. In: Leatherwood S, Reeves R (eds) The bottlenose dolphin. Academic Press, San Diego, CA, p 235-244

Shapiro SS, Wilk MB (1965) An analysis of variance test for normality (complete samples). Biometrika 52:591-611

> Stewart REA, Lavigne DM (1984) Energy transfer and female condition in nursing harp seals (Phoca groenlandica). Ecography 7:182-194

Tallis HM, Wing SR, Frew RD (2004) Historical evidence for habitat conversion and local population decline in a New Zealand fjord. Ecol Appl 14:546-554

Thayer VG, Read AJ, Friedlaender AS, Colby DR and others (2003) Reproductive seasonality of western Atlantic bottlenose dolphins off North Carolina, USA. Mar Mamm Sci 19:617-629 
Trites AW, Pauly D (1998) Estimating mean body masses of marine mammals from maximum body lengths. Can J Zool 76:886-896

Urian KW, Duffield DA, Read AJ, Wells RS, Shell ED (1996) Seasonality of reproduction in bottlenose dolphins, Tursiops truncatus. J Mammal 77:394-403

Vergara P, Aguirre J I, Fernández-Cruz M (2007) Arrival date, age and breeding success in white stork Ciconia ciconia. J Avian Biol 38:573-579

Wauters L, Dhondt AA (1989) Body weight, longevity and reproductive success in red squirrels (Sciurus vulgaris). J Anim Ecol 58:637-651

Wells RS, Tornero V, Borrell A, Aguilar A and others (2005) Integrating life-history and reproductive success data to examine potential relationships with organochlorine compounds for bottlenose dolphins (Tursiops truncatus) in Sarasota Bay, Florida. Sci Total Environ 349:106-119

Whitehead H, Mann J (2000) Female reproductive strategies of cetaceans. In: Mann J, Connor RC, Tyack PL, White-

Editorial responsibility: Robert Harcourt, Sydney, NSW, Australia head H (eds) Cetacean societies: field studies of dolphins and whales. The University of Chicago Press, Chicago, IL, p 219-246

Wickham H, Chang W (2015) Package 'ggplot2', an implementation of the grammar of graphics. https:// github.com/hadley/ggplot2

Williams JA, Dawson SM, Slooten E (1993) The abundance and distribution of bottlenose dolphins (Tursiops truncatus) in Doubtful Sound, New Zealand. Can J Zool 71: 2080-2088

Wilson B, Hammond PS, Thompson PM (1999) Estimating size and assessing trends in a coastal bottlenose dolphin population. Ecol Appl 9:288-300

Yeates LC, Houser DS (2008) Thermal tolerance in bottlenose dolphins (Tursiops truncatus). J Exp Biol 211: 3249-3257

Zuur AF, Ieno EN, Walker NJ, Savelieve AA, Smith GM (2009) Mixed models and extensions in ecology with R. Springer Science and Business, New York, NY

Submitted: July 17, 2015; Accepted: November 30, 2015 Proofs received from author(s): January 21, 2016 